\title{
Fluid substitution modelling and derived rock attribute-based discriminations of hydrocarbon and lithology: a case study of arcuate Niger Delta Depobelt, Nigeria
}

\author{
Aniefiok Sylvester Akpan ${ }^{1} \cdot$ Francisca Nneka Okeke ${ }^{1} \cdot$ Daniel Nnaemeka Obiora ${ }^{1} \cdot$ Johnson Cletus Ibuot ${ }^{1}$
}

Received: 8 September 2020 / Accepted: 6 November 2020 / Published online: 20 November 2020

(c) Springer Nature Switzerland AG 2020

\begin{abstract}
Fluid substitution modelling was carried out to discriminate the formation fluids in $X$-field. The study employed 3D seismic volume and well logs from two exploratory wells. Two reservoir sands, labelled HD3000 and HD5000, were delineated based on the well signatures of gamma ray and resistivity logs. These reservoir zones are thicker in well $X 2$ than in well $X 1$. Saturations of fluid in the delineated reservoirs were varied using $50 \%$ for brine, gas and oil scenarios. The main goal of the study is to distinguish the formation fluid present in the reservoirs based on the crossplot of the fluid replacement modelling scenarios. The crossplot of P-impedance versus S-impedance attributes revealed separation in clusters representing the scenarios for the different fluid saturations in the reservoirs. A clear distinction was deciphered between fluid and lithology in the field based on the clusters of crossplots. The synthetic result revealed positive increase in amplitude at the reservoir tops for brine saturation, while positive decrease in amplitude were depicted in the case of oil and gas saturations. P-wave decreased more with $50 \%$ brine saturation when compared to the decrease with $50 \%$ gas/oil saturation scenarios. The inverted P-impedance amplitude slice reveals four (4) zones labelled $\mathrm{H} 1, \mathrm{H} 2 \mathrm{H} 3$ and $\mathrm{H} 4$ suspected to be saturated with probable hydrocarbon accumulation based on the low impedance observed around the inferred zones.
\end{abstract}

Keywords Reservoir · Saturation $\cdot$ Crossplot $\cdot$ Modelling $\cdot$ Fluid $\cdot$ Hydrocarbon

\section{Introduction}

As the increasing demand for hydrocarbon continues to rise astronomically in a global scale due to technology and population explosion, tertiary hydrocarbon recovery methods have been developed and advanced to increase production in new and old oil/gas fields. The quest to discover more potential hydrocarbon traps for exploration has led to various developments in the oil/gas production sector. Exploration and exploitation of an anomaly inferred to be reservoir saturated with hydrocarbon require a detailed description of the probable zone. The description includes amongst other requirements, the type of formation fluid present in reservoir and the volume of saturation.
Since hydrocarbon reservoirs are originally saturated with water before the migration of matured organic matter at the completion of cooking into the reservoir, a reservoir rock is then found to be saturated with oil, gas and irreducible water. Thus, it is necessary to discriminate the fluid in order to ascertain the chance of hydrocarbon saturation in the reservoir considered for exploration.

The in situ log response measured during well logging represents a combination of the influence from the rock and fluids present in the reservoir at the time of logging. The separation and quantification of these formation fliuds in the reservoir play key role in determining the amount of hydrocarbon available for production. This process referred to as reservoir characterization depends

Aniefiok Sylvester Akpan, aniefiok.akpan.pg79875@unn.edu.ng| 'Department of Physics and Astronomy, University of Nigeria, Nsukka, Enugu State, Nigeria. 
Fig. 1 Niger Delta Depobelt Map where the study area is situated [13]

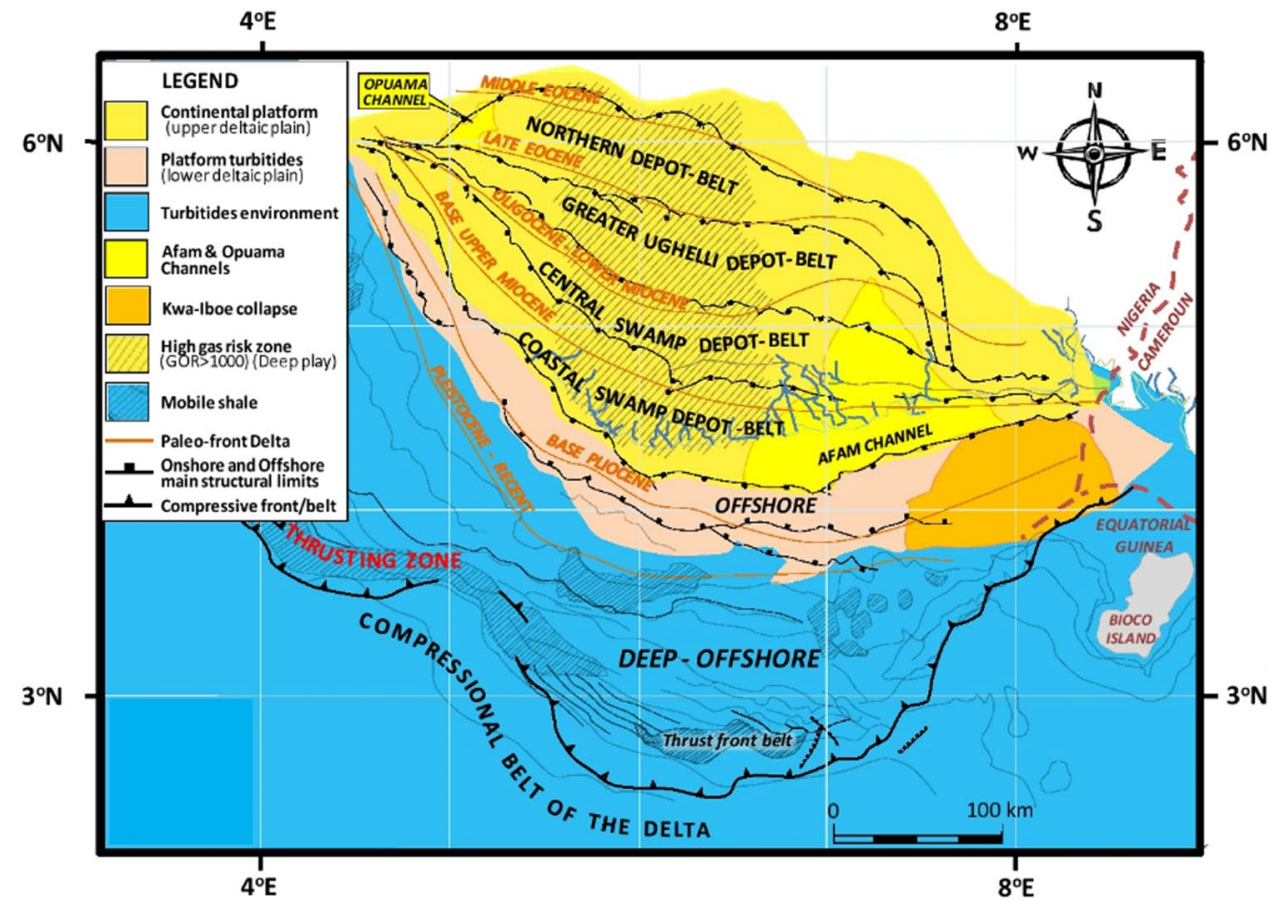

mostly on the prediction of lithology and fluid discrimination. A major challenge in hydrocarbon exploration lies in the need for proper mapping of the reservoir and its characterization to determine the economic value of such a field [1]. Although several techniques exist in the characterization of hydrocarbon field in search for probable reservoir saturated with commercial hydrocarbon for exploration, Gassmann relations are the most commonly and widely used equation worldwide. Several researchers have employed Gassmann fluid replacement modelling in the characterization of hydrocarbon reservoirs across the globe [2-5]. Since the discovery of hydrocarbon in the
Fig. 2 Niger Delta Basin stratigraphic column showing the Akata, Agbada and Benin Formations [20]

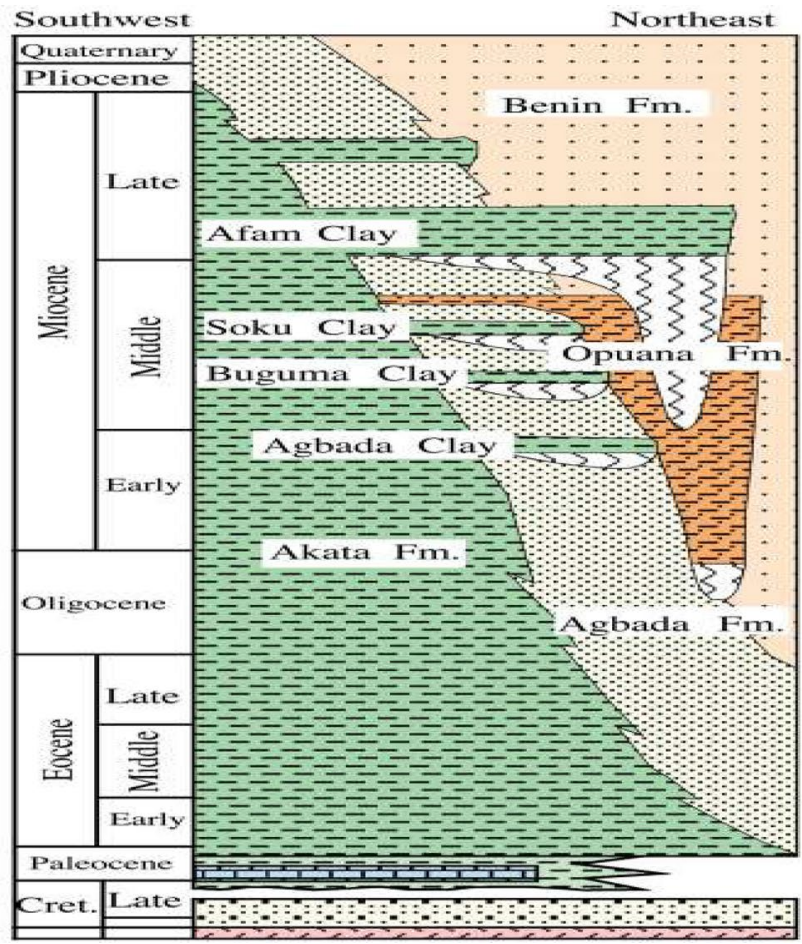


Niger Delta, the extensive exploration activities carried out over the years have made the basin to be regarded as one of the World's major hydrocarbon provinces $[2,6]$. The quest to further increase the production of hydrocarbon in the Basin has led to the application of various geophysical methods of reservoir characterization ranging from seismic inversion, amplitude variation with offset (AVO) to petrophysical analysis [7-9].

Interpretation of seismic amplitude depends on the understanding of how rock properties are affected by varying fluid saturation change-from hydrocarbon fill rock to brine fill rock. The conventional method of discriminating fluid and lithology using rock attribute crossplot depends on converging clusters in the crossplot space. Generally, the crossplot clusters are usually observed to plot along a background trend with the different formation fluids (oil, gas and water) and lithology inferred based on the variation in values of the converging clusters. The fluid substitution modelling technique is a significant tool as it enables the prediction of elastic response of a rock saturated with one type of fluid from the elastic response of the same rock saturated with another fluid [10]. The innovation of fluid substitution modelling in seismic reservoir characterization has so far promoted breakthrough in the exploration of oil and gas. One of such breakthroughs is the success of the technique in time lapse ( $4 D$ seismic) method of delineating bypassed oil/gas prospects, which have a lot of economic value to oil/gas industries. This study thus aims to discriminate the formation fluid (oil, gas and brine) and delineate possible accumulation for exploration target in the field, which will contribute to increase in hydrocarbon production.

\section{Geology of the study area}

The study area identified as $X$-field is one of the oil exploration fields located in the prolific arcuate Niger Delta Depobelt (Fig. 1). The Niger Delta Basin is situated on the continental margin of the Gulf of Guinea in equatorial West Africa at the southern end of Nigeria bordering the Atlantic Ocean. The basin lies between latitudes $3^{\circ} \mathrm{N}$ and $6^{\circ} \mathrm{N}$ and longitudes $4^{\circ} \mathrm{E}$ and $8^{\circ} \mathrm{E}[11-13]$. The study location falls under one of the world most explored Sedimentary Basins. Since the early discovery of commercial hydrocarbon in 1956, extensive exploration and exploitation of hydrocarbon in the basin has led to the acquisition of several seismic data ranging from $2 D, 3 D$ to $4 D[11,13]$. The Niger Delta Basin covers an area of about 75,000 square kilometres, and its formation is attributed to the buildup of sediment associated with rift faulting during the Precambrian. The recognized reservoir rocks in the Basin are
Fig. 3 Summarized workflow illustrating the study methodology

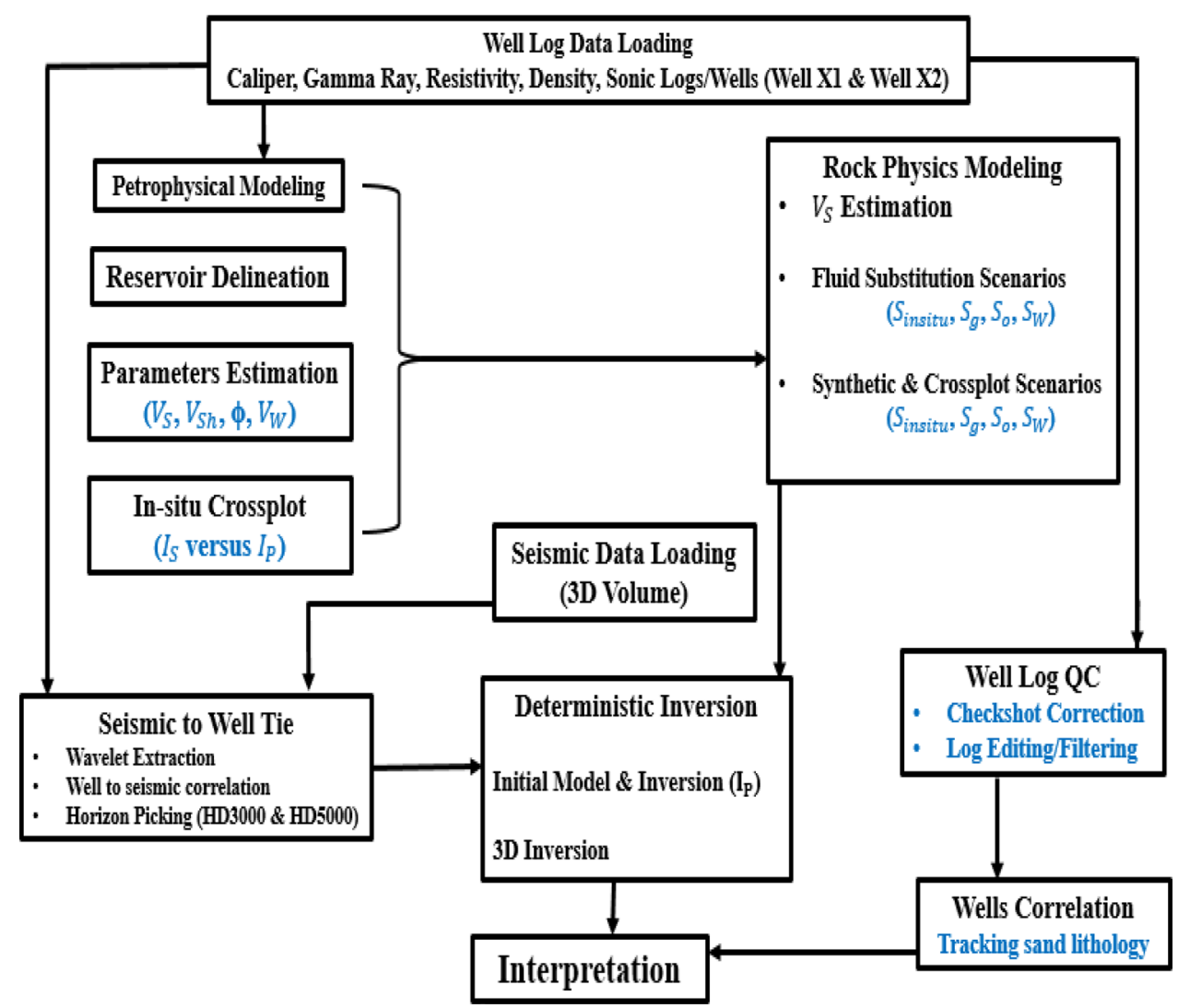

SN Applied Sciences A SPRINGER NATURE journa 


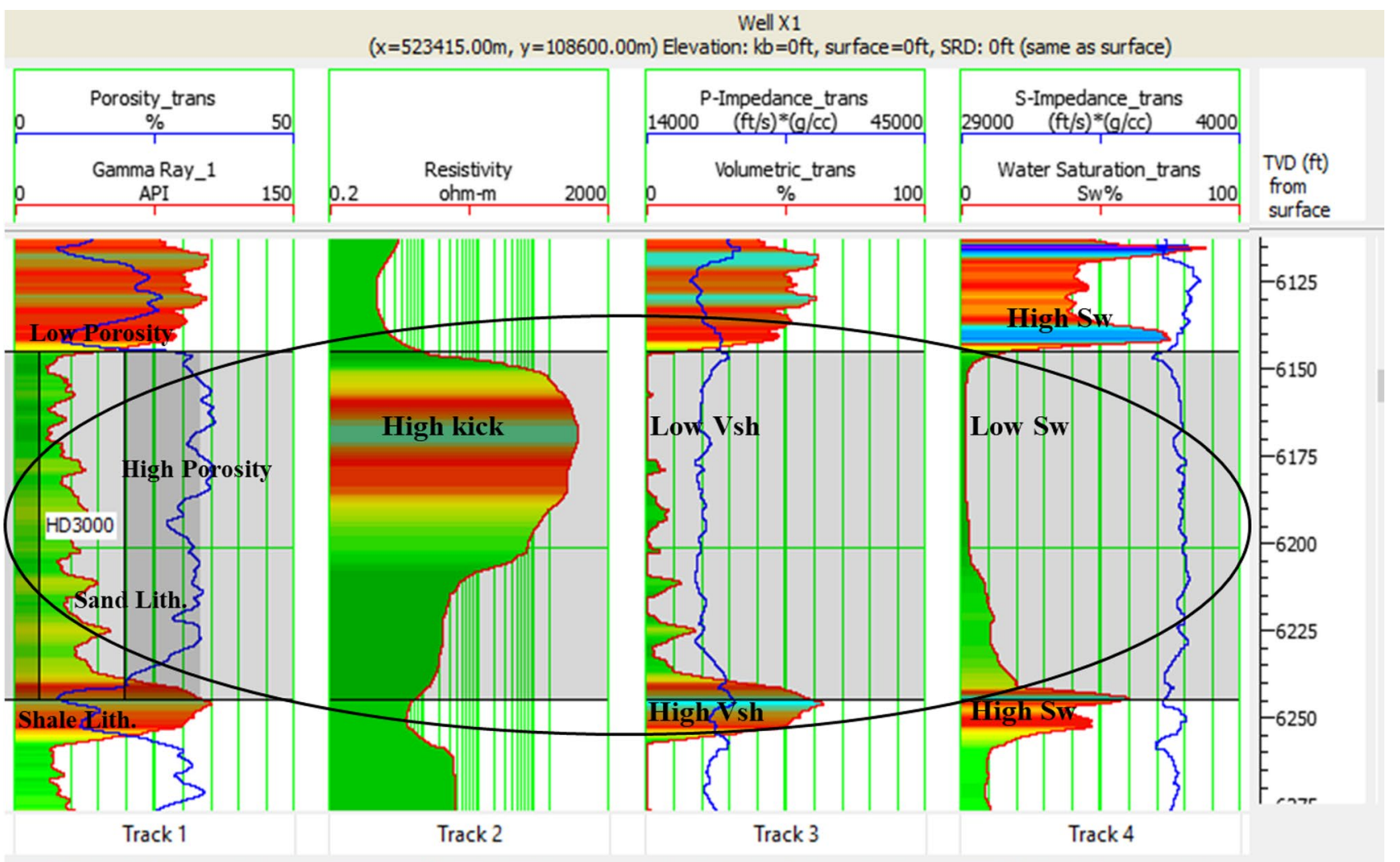

Fig. 4 Well $X 1$ showing delineated HD3000 reservoir and estimated reservoir parameters

of Eocene to Pliocene in age [14]. The Tertiary Niger Delta is subdivided into three lithostratigraphic successions, the Akata, Agbada and Benin Formations (Fig. 2). These formations according to [15] depict massive coarsening-upward progradational clastic wedge deposited in fluvial, deltaic and marine environments $[16,17]$. The Akata Formation is of marine origin and is composed of turbidites sand and minor amount of clays and silt. The shales serve as potential source for hydrocarbon in the Delta [18]. In deep water, the turbidite sands are the potential reservoir rocks. The Agbada Formation is overlain by the Benin Formation-a Coastal Plain sand. [19], estimated the sand percentage of the Agbada Formation to be between 30 and $70 \%$ and attributed its variation to the large number of depositional off lap cycles. The Agbada Formation is the main reservoir rock in the Niger Delta Basin. The top part of the Niger Delta clastic wedge is the Benin Formation. The formation consists of mainly sands and gravel which serves as water bearing rocks in the continental regions.

\section{Conceptual framework}

Extraction of fluid types or saturations from seismic, crosswell, or borehole sonic data requires a procedure to model fluid effects on rock velocity and density [4]. Fluid substitution modelling is done to obtain the sensitivity of the seismic response with different fluid saturation in the reservoir pores. The technique provides an interpreter with a reliable tool for modelling and quantifying the various fluid scenarios which might give rise to an observed AVO of 4D response [21]. The modelling of reservoir rocks gives an interpreter the possibility to compare the well data and the expected seismic response. Seismic reflection response varies due to some factors such as lithology, rock matrix composition, layer thickness and depth as well as changes in the fluid type, either from brine to oil or gas to oil. This according to [22] can be resolved using fluid substitution modelling because the technique enables the understanding and prediction of how seismic velocity and impedance depend on pore fluids. Though different methods abound in modelling rock response to varying fluid saturations, [23] relation given in Eq. 1 is the most reliable expression employed in calculating the changes in seismic velocity in reservoir rocks saturated with different fluids. This equation estimates the elastic properties 


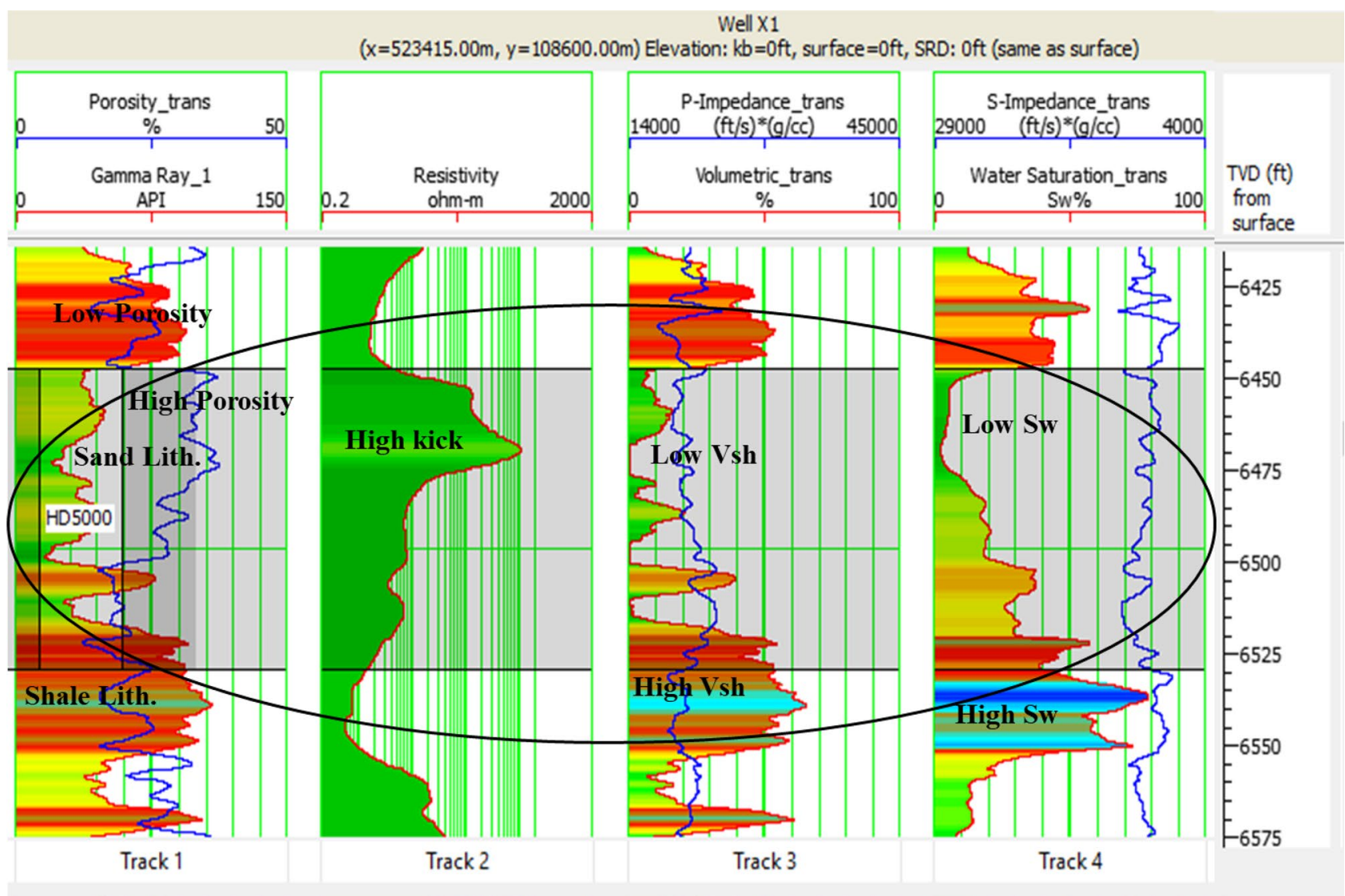

Fig. 5 Well $X 1$ showing delineated HD5000 reservoir and estimated reservoir parameters

at the desired saturation from either the dry rock or fluidsaturated rock [24].

$K_{\text {sat }}=K_{\text {dry }}+\frac{\beta^{2}}{\left(\frac{\phi}{K_{\mathrm{f}}}+\frac{\beta-\phi}{K_{\text {ma }}}\right)}$

where $\phi$ is the porosity, $K_{\text {sat }}$ is the bulk modulus of the saturated rock, $K_{\mathrm{dry}}$ is the bulk modulus of the dry rock, $K_{f}$ is the bulk modulus of the fluid assumed known, and $K_{\mathrm{ma}}$ is the bulk modulus of the mineral component usually assumed known. $\beta$ is called the Biot Coefficient, the ratio of volume changes in the fluid to the volume change in the formation given in Eq. 2 as:

$\beta=1-\frac{K_{\mathrm{dry}}}{K_{\mathrm{ma}}}$

Substituting Eq. 2 into 1 gives Eq. 3;

$K_{\mathrm{sat}}=K_{\mathrm{dry}}+\frac{\left(1-\frac{K_{\mathrm{dry}}}{K_{\mathrm{ma}}}\right)^{2}}{\left(\frac{\phi}{K_{\mathrm{f}}}+\frac{1-\phi}{K_{\mathrm{ma}}}+\frac{K_{\mathrm{dry}}}{K_{\mathrm{ma}}^{2}}\right)}$
This equation gives a relationship between the bulk modulus of the rock, its frame, pore, and fluid properties. This method of fluid modelling requires that the effect of the starting fluid first be removed prior to modelling the new fluid [21]. These give more intuitive insight into the effect of pore fluid on the bulk modulus and P-wave velocity of the formation under consideration.

\section{Materials and methodology}

The dataset used for this work includes 3D seismic volume and suites of well logs data with relevant log information from two exploratory wells labelled well $X 1$ and well $X 2$. The well logs comprise gamma ray, resistivity, caliper, sonic, density and well reservoir markers. These data were acquired from $X$-field operating in the prolific arcuate Niger Delta Basin. Well log quality control (QC) was applied to the well data to correct for spikes, which could be present in the data as a result of noise and logging effect. The QCs carried out on the log data were: log editing, filtering and checkshot correction. Sonic logs were checkshot corrected to correct for discrepancies in the sonic derived 


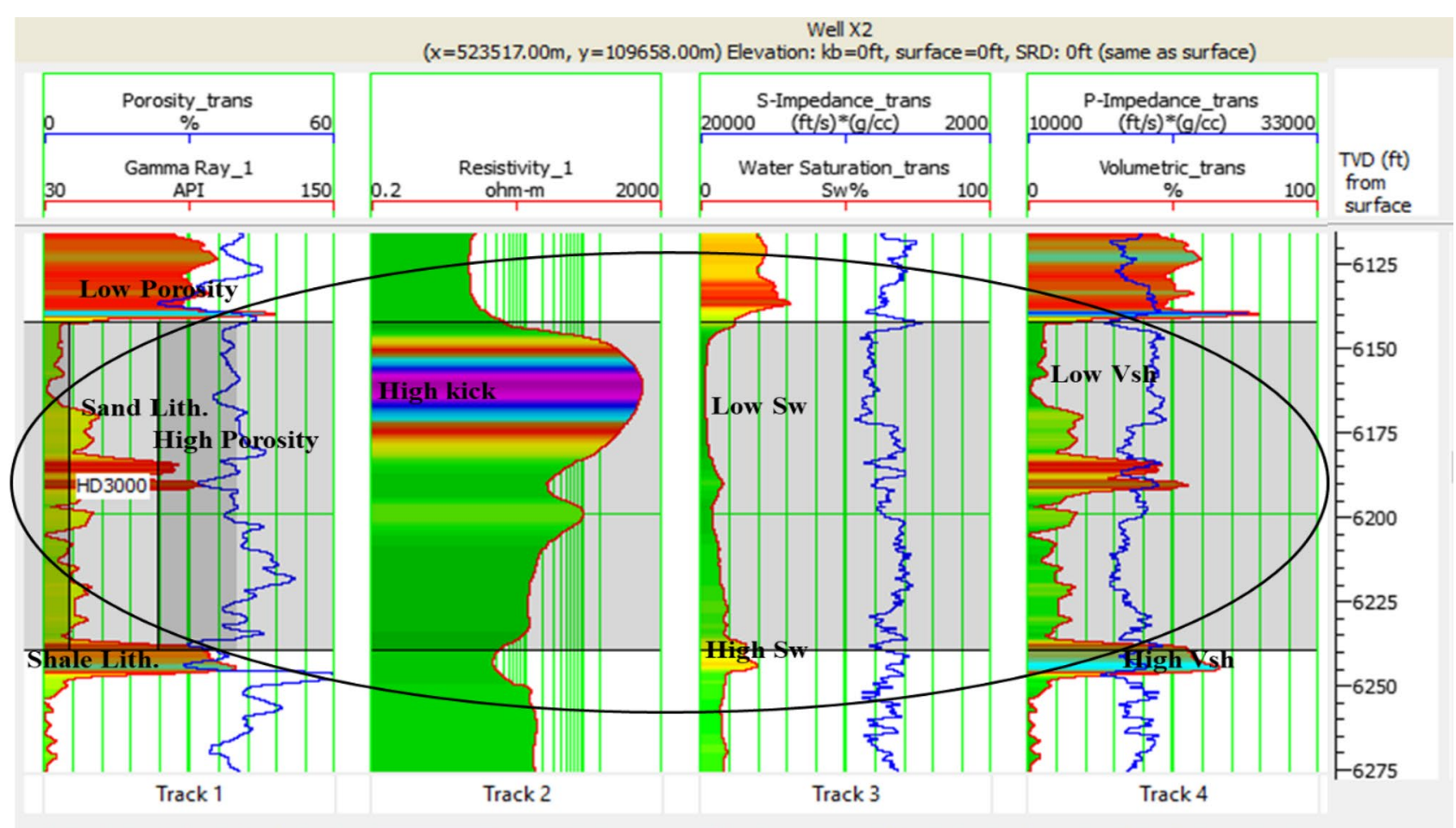

Fig. 6 Well X2 showing delineated HD3000 reservoir and estimated reservoir parameters

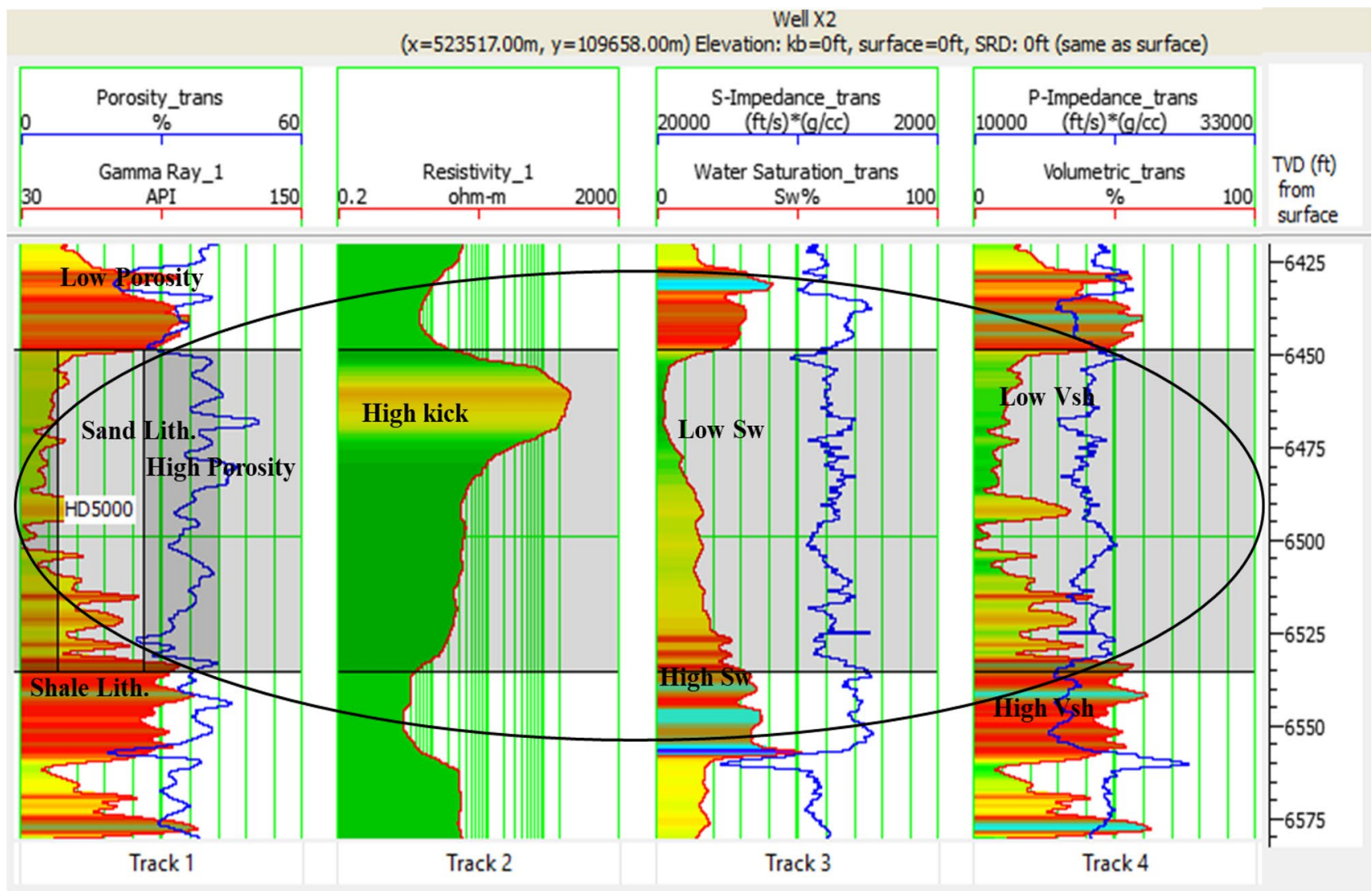

Fig. 7 Well $X 2$ showing delineated HD5000 reservoir and estimated reservoir parameters 


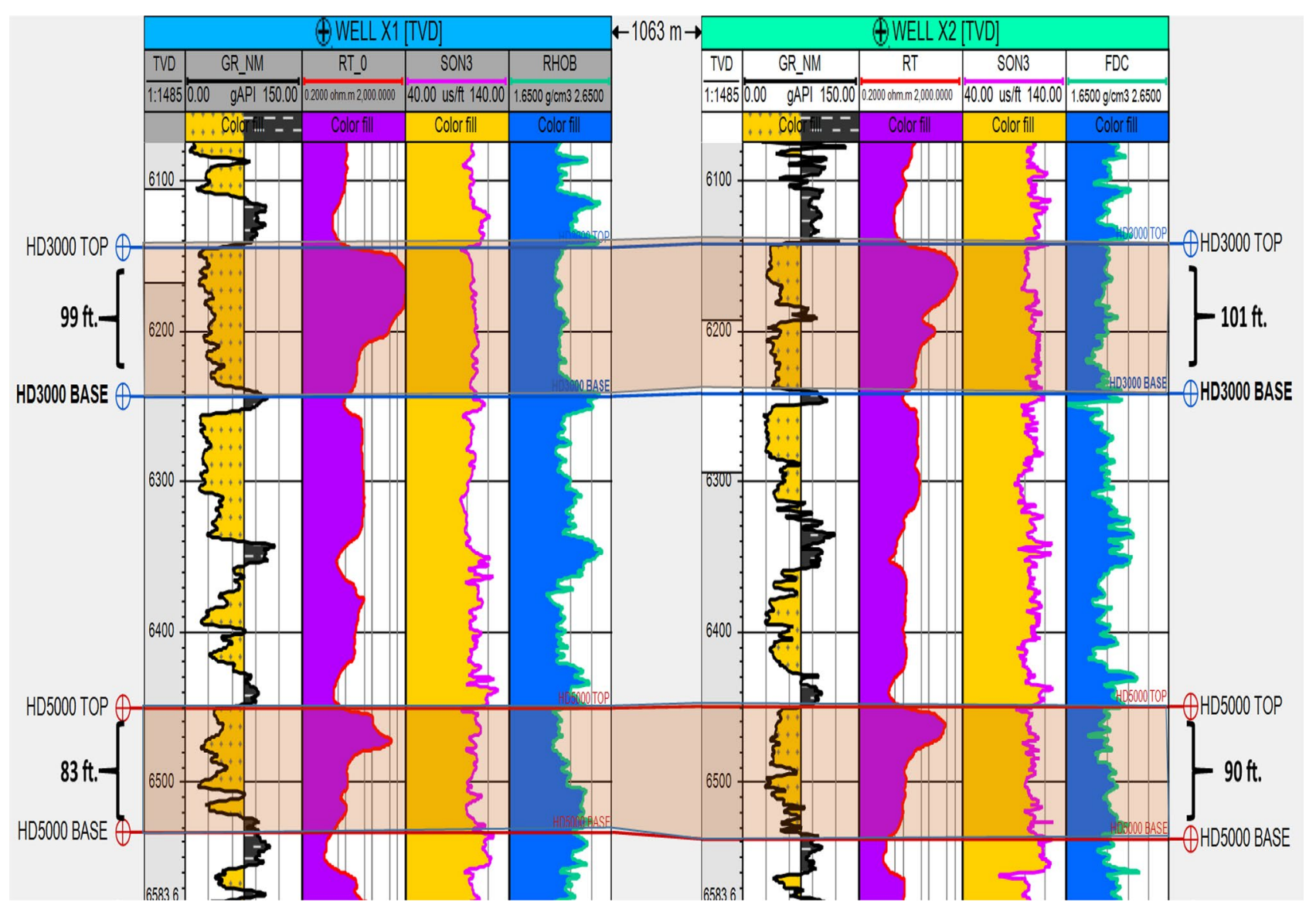

Fig. 8 Well-to-well correlation of well $X 1$ and well $X 2$ showing variation in reservoir thickness

P-wave curve. This was followed by log filtering, which was carried out using an operator length of six (6). The chosen operator length was found suitable to remove spikes and preserve signal in the data. Petrophysical modelling was carried out to delineate reservoir and compute the reservoir parameters of the selected zones. The reservoirs identified and labelled HD3000 and HD5000 were delineated based on high resistivity and low gamma ray log curve. Reservoir parameters such as porosity, water saturation, and volume of shale factor within the delineated reservoir zones were estimated to ascertain the zones as probable reservoirs. The formation porosity was estimated using relation given in Eq. 4 as:

$\phi=\frac{\rho_{\mathrm{ma}}-\rho_{\mathrm{b}}}{\rho_{\mathrm{ma}}-\rho_{\mathrm{f}}}$ where $\rho_{b}$ is the bulk density of the formation, $\rho_{\mathrm{ma}}$ is the density of the rock matrix, and $\rho_{\mathrm{f}}$ is the density of the fluids occupying the pore spaces.

Water saturation was estimated using [25] relation given in Eq. 5 as:

$S_{\mathrm{W}}^{n}=\frac{a}{\phi^{m}} \times \frac{R_{\mathrm{W}}}{R_{\mathrm{t}}}$

where $a$ is the cementation factor, $m$ is the cementation exponent, $R w$ is resistivity of the formation water, and $n$ is the saturation exponent.

Volume of shale $\left(V_{\mathrm{sh}}\right)$, which gives a measure of the amount of shale in a chosen reservoir zone, was estimated using [26] relation given in Eq. 6. Shaliness plays a key role in the delineation of formation lithology. Proper 


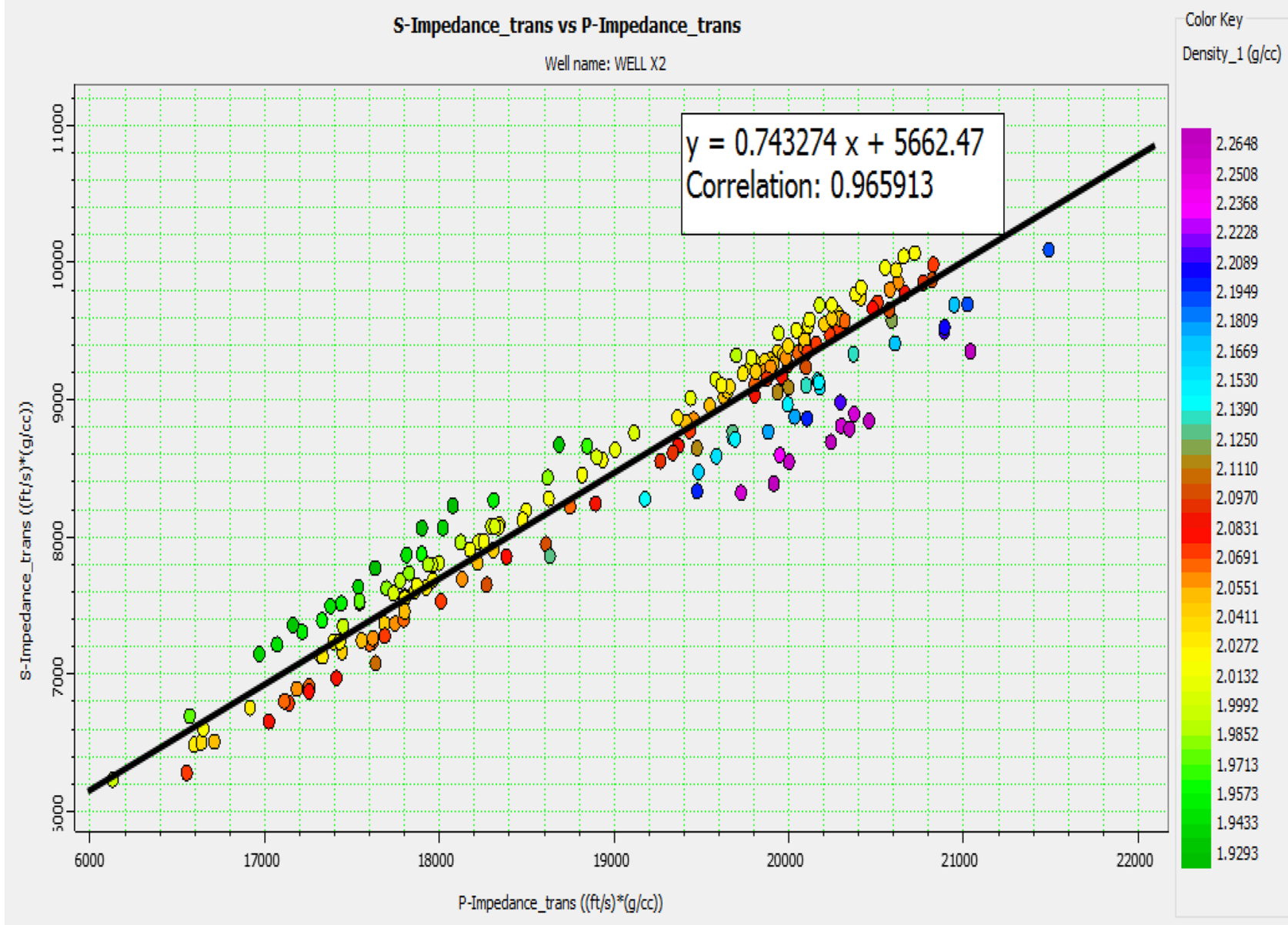

Fig. 9 In-situ crossplot of shear impedance $\left(I_{S}\right)$ versus acoustic impedance $\left(I_{P}\right)$

estimation of shale content provides the basis for accurately deriving the other petrophysical parameters such as porosity and water saturation.

$V_{\text {sh }}=0.083 \times\left[2^{(3.7 \times \mid G R)}-1\right]$

From the relation given in Eq. 6, formations are identified as clean, shaly, or shale zones based on the $V_{\text {sh }}$ cut-offs values obtained. The cut-offs are grouped as:

1. $V_{\text {sh }}<10 \%$ implies a clean sand [27],

2. $V_{\text {sh }}$ values of $10-35 \%$ implies shaly sand

3. $V_{\text {sh }}>35 \%$ implies a shale zone [28]. where IGR is the gamma ray index given in Eq. 7 as:

$I G R=\frac{G R_{\log }-G R_{\min }}{G R_{\max }-G R_{\min }}$

$G R_{\text {log }}$ is the $G R$ value of the formation measured from $\log , G R_{\min }$ is the $G R$ minimum value of clean sand, and $G R_{\max }$ is the $G R$ maximum value of the shale beds. These estimated reservoir parameters were all serving as input parameters for the rock physics modelling carried out using Gassmann FRM (fluid replacement modelling) relation. S-wave was estimated for the well using [29] relations for sand and shale beds given in Eqs. 8 and 9, respectively. These Eqs. 8 and 9 were employed to estimate S-wave 


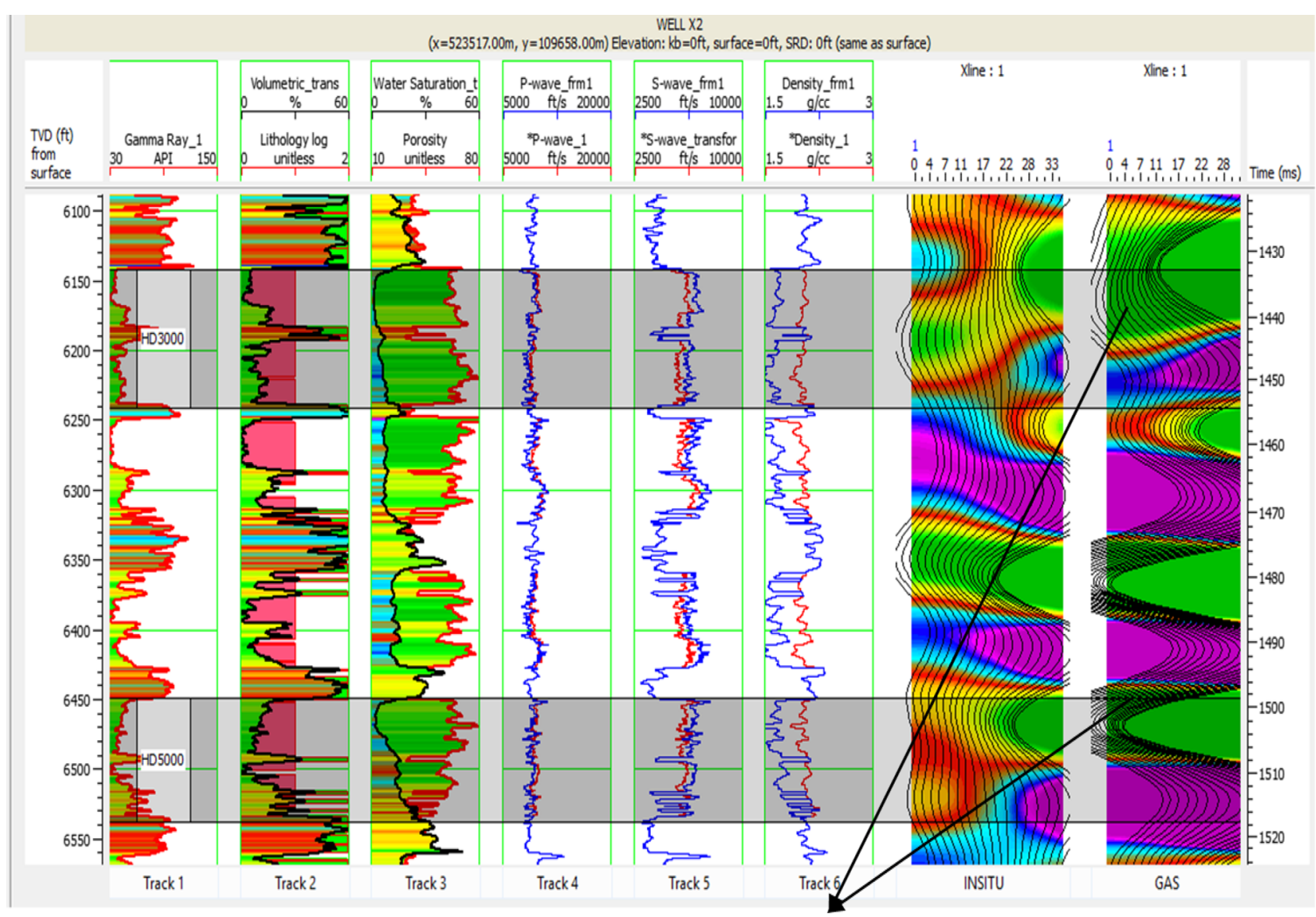

Increase in amplitude negatively

Fig. 10 Gas substitution showing in situ and the generated synthetic traces of gas model

because the well log data employed in this study does not have S-wave logging information for the two wells. Reference [29] is a widely used empirical relation for shear wave velocity log estimation across the globe. The summarized workflow illustrating the study methodology is shown in Fig. 3.

$V_{S}=(0.80416) V_{P}-0.85588$

$V_{\mathrm{S}}=(0.76969) V_{\mathrm{P}}-0.86735$

Fluid substitution modelling was carried out using [23] fluid replacement relation given in Eq. 3. Saturations were varied for oil, gas and brine using $50 \%$ saturation increment for each case scenario. Different fluid saturation scenarios were created for the two delineated reservoir zones. The delineated reservoirs HD3000 and HD5000 were first set to be flooded with more of gas saturations. This was done by injecting fifty percent (50\%) gas into the reservoir in order to make the prospect to be $50 \%$ gas, $25 \%$ oil and $25 \%$ brine saturated. For the second case, $50 \%$ oil was injected into the delineated reservoirs to create a scenario saturated with more oil. The injection of $50 \%$ oil into the delineated reservoirs creates a reservoir model scenario of $25 \%$ brine, $25 \%$ gas and $50 \%$ oil-saturated prospects. In third case, the reservoir was made to be more of brine saturated by injecting $50 \%$ brine into the reservoir in order to clearly distinguish the effect that will occur when brine is introduced into the reservoir. The 


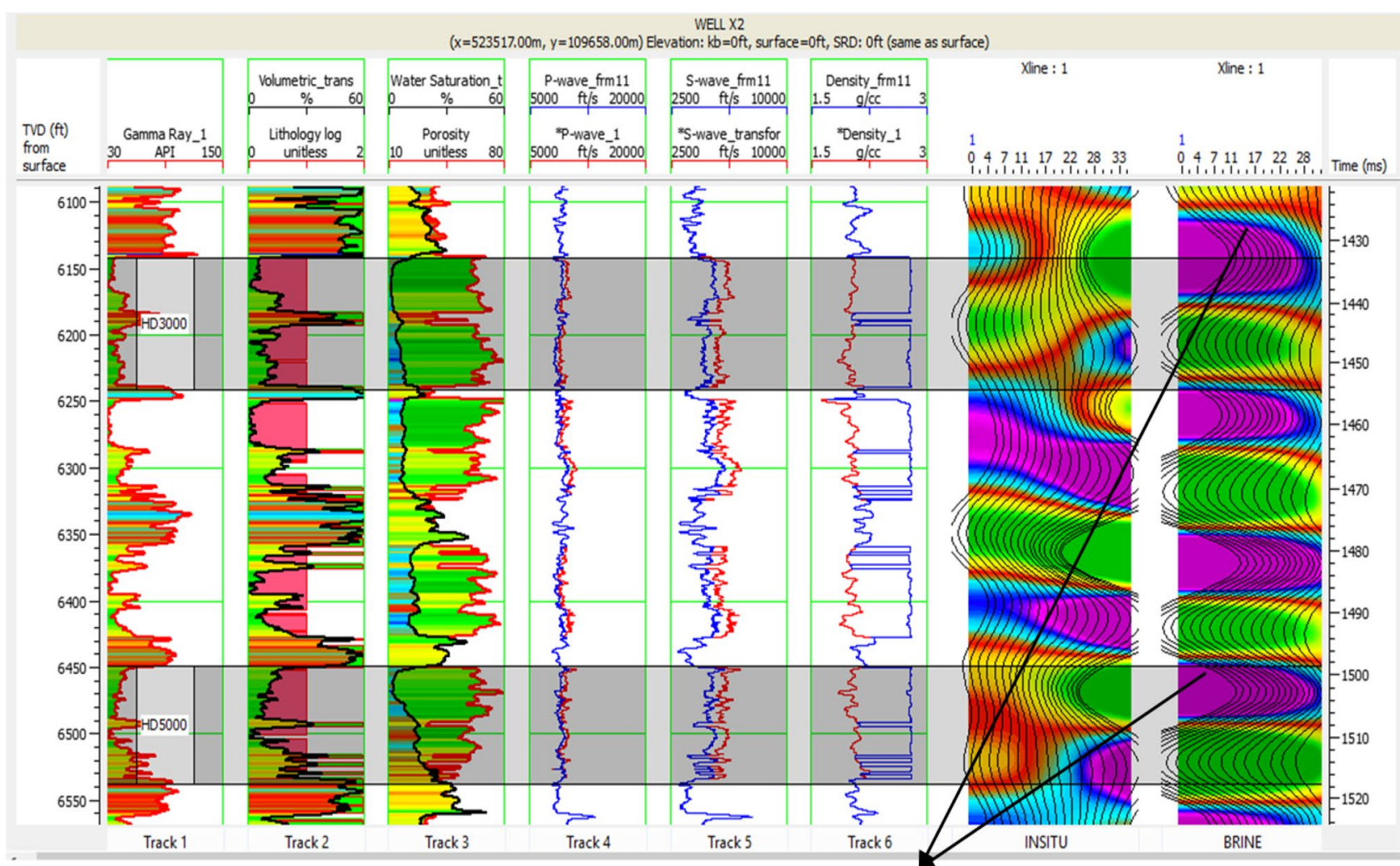

Increase in amplitude positively

Fig. 11 Brine substitution showing in situ and the generated synthetic traces of brine model

brine model was created after $50 \%$ brine was injected into the reservoir, which produces a scenario of $25 \%$ gas, $25 \%$ oil and $50 \%$ brine-saturated scenario. The response of density, P-wave, acoustic impedance (AI), S-wave and Poisson's ratio for each case scenario was observed and their respective synthetic curves generated.

\section{Results and discussion}

The formation properties of $X$-field were inferred from the digital log signatures of the two wells shown in Figs. 4, 5, 6 and 7. The log signature curves depict the delineated reservoir sands designated as HD3000 and HD5000, which are circled in black polygon. These zones HD3000 and HD5000 were mapped based on the petrophysical results obtained and the relationship between the gamma ray and resistivity log curve response. The delineated reservoir zones are characterized with low gamma ray curve, which corresponds to sand lithology and high resistivity curve. The estimated reservoir parameter curves reveal values which are typical of hydrocarbon-saturated rock. Sand, sand/ shale and shale alternations are the lithologic sequence inferred from the well log interpretations. These lithologic units are typical of the Niger Delta Formation lithologic sequence where the study area is situated. Gamma ray values of less than $(<60 \mathrm{API})$ were observed for the sand lithology while shale beds are characterized with gamma ray values greater than (>60 API) in track 1 of the well log section (Figs. 4, 5, 6, 7). The variation in water saturation is 


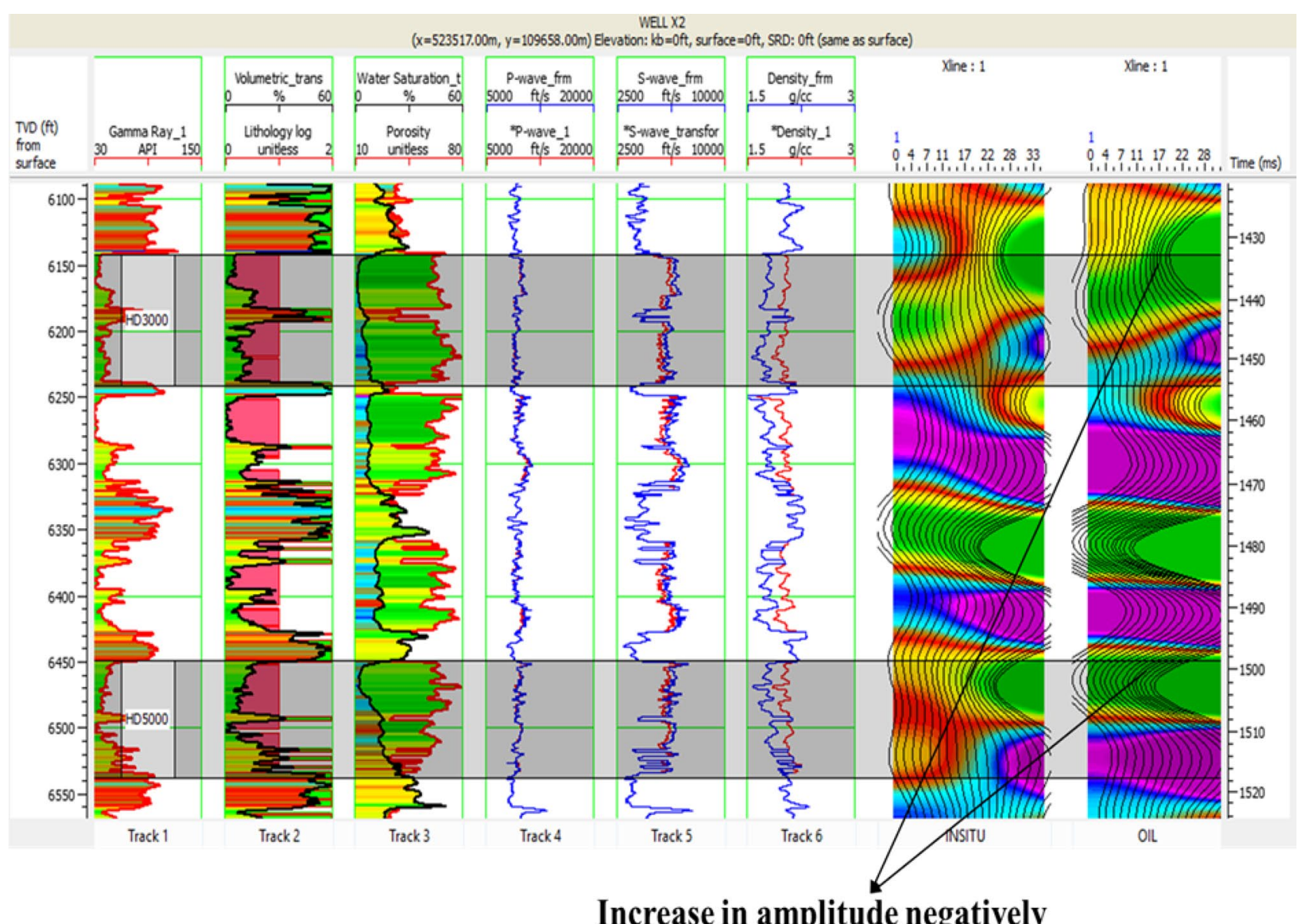

Fig. 12 Fluid substitution for $50 \%$ oil saturation in blue log curve and in situ red curve

such that water saturation is less than $10 \%$ and increases towards the base of the delineated reservoirs (HD3000 and HD5000). The observed increase in water saturation can be attributed to the shale intrusion as observed in the corresponding gamma ray log curve around the zone with high water saturation. Porosity is high within reservoir zones and decreases in the shale bed, which serves as a cap at the top and base of the reservoir. The reservoir zones exhibit excellent effective porosity $(>30 \%)$ when compared to the standard porosity values given by [30]. Estimated reservoir parameters vary accordingly within the delineated reservoir zones. Volume of shale $\left(V_{\text {sh }}\right)$ was found to be high outside the reservoir zones and low within the reservoirs $(<25 \%)$. Within the reservoirs, shale volume increases in region with intercalated sand/shale and shale intruded region.

The well-to-well correlation of the wells $X 1$ and $X 2$ reveals variation in thicknesses and down dip between the well locations and the delineated sand reservoirs of HD3000 and HD5000 (Fig. 8). The delineated reservoir sands are thicker in well $X 2$ than in well $X 1$. This implies that more sedimentation of the sand unit occurred around the location of well $X 2$. The reservoirs range from 6150 to $6249 \mathrm{ft}$ and 6450 to $6533 \mathrm{ft}$ in well $X 1$ for HD3000 and HD5000, respectively, while in well $X 2$ the reservoirs ranged from 6144 to $6245 \mathrm{ft}$ and 6450 to $6540 \mathrm{ft}$ for 


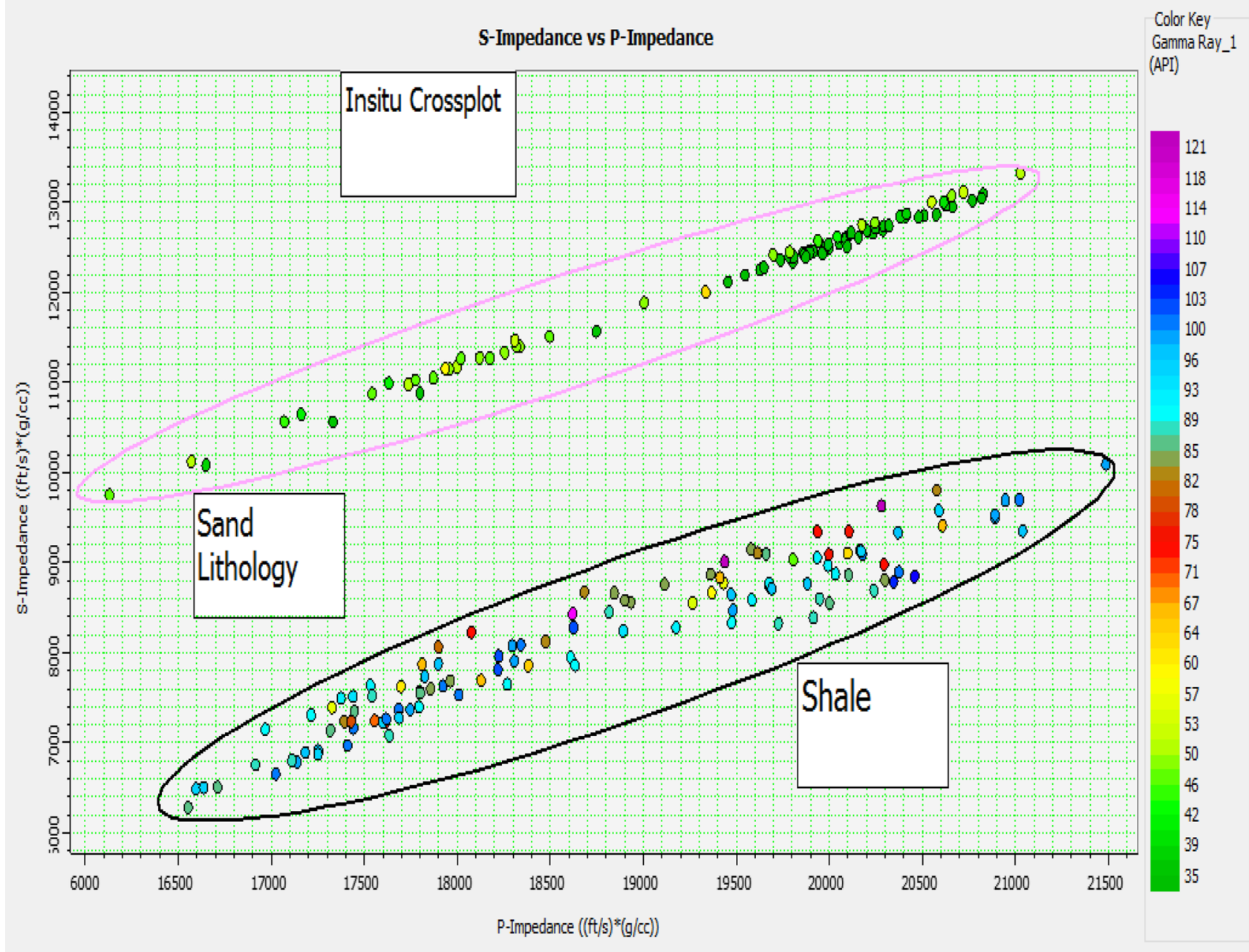

Fig. 13 S-impedance versus P-impedance crossplot separating the two dominant lithologies in the field

HD3000 and HD5000, respectively. These ranges of values give a reservoir thickness of $99 \mathrm{ft}$ and $83 \mathrm{ft}$ in well $X 1$, while well $X 2$ ranged from $101 \mathrm{ft}$ and $90 \mathrm{ft}$.

\subsection{In situ crossplot result of S-impedance against $P$-impedance}

The in situ crossplot space of S-impedance $\left(I_{S}\right)$ against P-impedance $\left(I_{\mathrm{p}}\right)$ within the selected reservoir zone is shown in Fig. 9. This crossplot was established to discriminate the lithology and formation fluid in the probable reservoirs. As stated by [31], crossplot results aided in the detection of anomalies, which depict the presence of hydrocarbon. The in situ crossplot gives no distinct separation between the clusters in terms of fluid and lithology, rather the plots show clusters along a wet trend line. The green clusters, which reflect region with low density from the colour key, are the hydrocarbon sand, the yellow to red colour range depicts wet sand while the cyan to purple are the shale beds in the field.

\subsection{Fluid replacement modelling for brine, gas and oil saturation scenarios}

As pointed out by [21], fluid substitution is an important part of seismic attribute studies as it provides the interpreter with valuable tool for modelling various fluid scenarios. These model results from Gassmann fluid replacement, to some extent, give a clue to the observed amplitude variations with offset anomaly. Figures 10, 11 and 12 are the results of fluid substitution for the three case scenarios considered in this study-the gas, brine and oil saturations, respectively. Within the two reservoirs, HD3000 and HD5000, different fluid saturations give rise to various changes in the reservoir properties and variations in P-wave, S-wave, density and P-impedance. In Fig. 10, the injection of $50 \%$ gas into the reservoirs causes the 


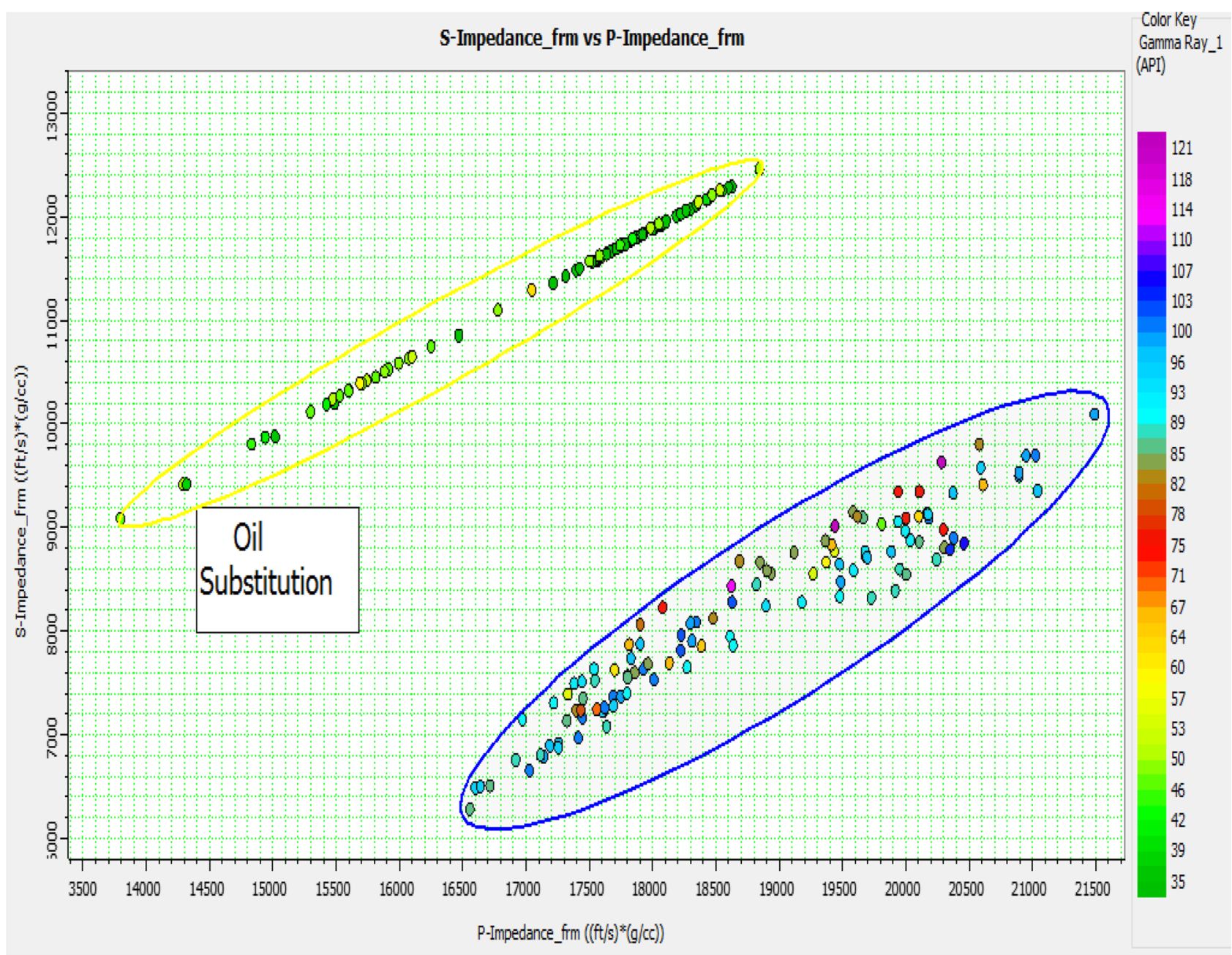

Fig. 14 S-impedance versus P-impedance crossplot space for oil injection

in situ P-wave (red curve) to decrease as indicated by new $\mathrm{P}$-wave plot shown in blue curve. The variation in density is such that density decreases more with $50 \%$ gas injection when compared to the second case where brine saturation was increased by injecting $50 \%$ brine into the model. For S-wave, reverse is the case as the $50 \%$ gas injection caused increase in S-wave from the in situ (red curve) to new injected S-wave (blue curve) within the delineated HD3000 and HD5000 reservoir sands.

The result of the second case is shown in Fig. 11 in which the saturation of brine was increased by injecting $50 \%$ brine into the reservoirs. The substitution of $50 \%$ brine into the reservoirs results in a model with different changes in P-wave, S-wave and density log curves in the two reservoirs, HD3000 and HD5000. The in situ P-wave (red curve) decreased to the new $50 \%$ saturated scenario deciphered in blue curve. Also, S-wave decreases more when the reservoir is filled with brine compared to the variation in $\mathrm{P}$-wave. For this case scenario, density variation with brine injection depicts high increase in the delineated reservoir zones when compared with the in situ. This is a reverse with the situation when gas saturation was increased by $50 \%$ where there was a more decrease in density. The third case scenario result is shown in Fig. 12 where oil saturation in the delineated reservoir zones was increased by $50 \%$. P-wave, S-wave and density log curves changed with the variation in fluid saturation within the reservoirs HD3000 and HD5000. S-wave increases more when the reservoir is saturated with $50 \%$ gas saturation compared to the variation in S-wave with $50 \%$ oil saturation. For this case scenario, density variation with oil injection decreases in the delineated reservoir zones when compared with the in situ. The different changes observed in P-wave, S-wave and density in the two reservoirs HD3000 and HD5000 confirm the effect of different fluid saturations on the response of these parameters.

The corresponding synthetic scenario created for gas, brine and oil substitution is shown in the last two tracks 


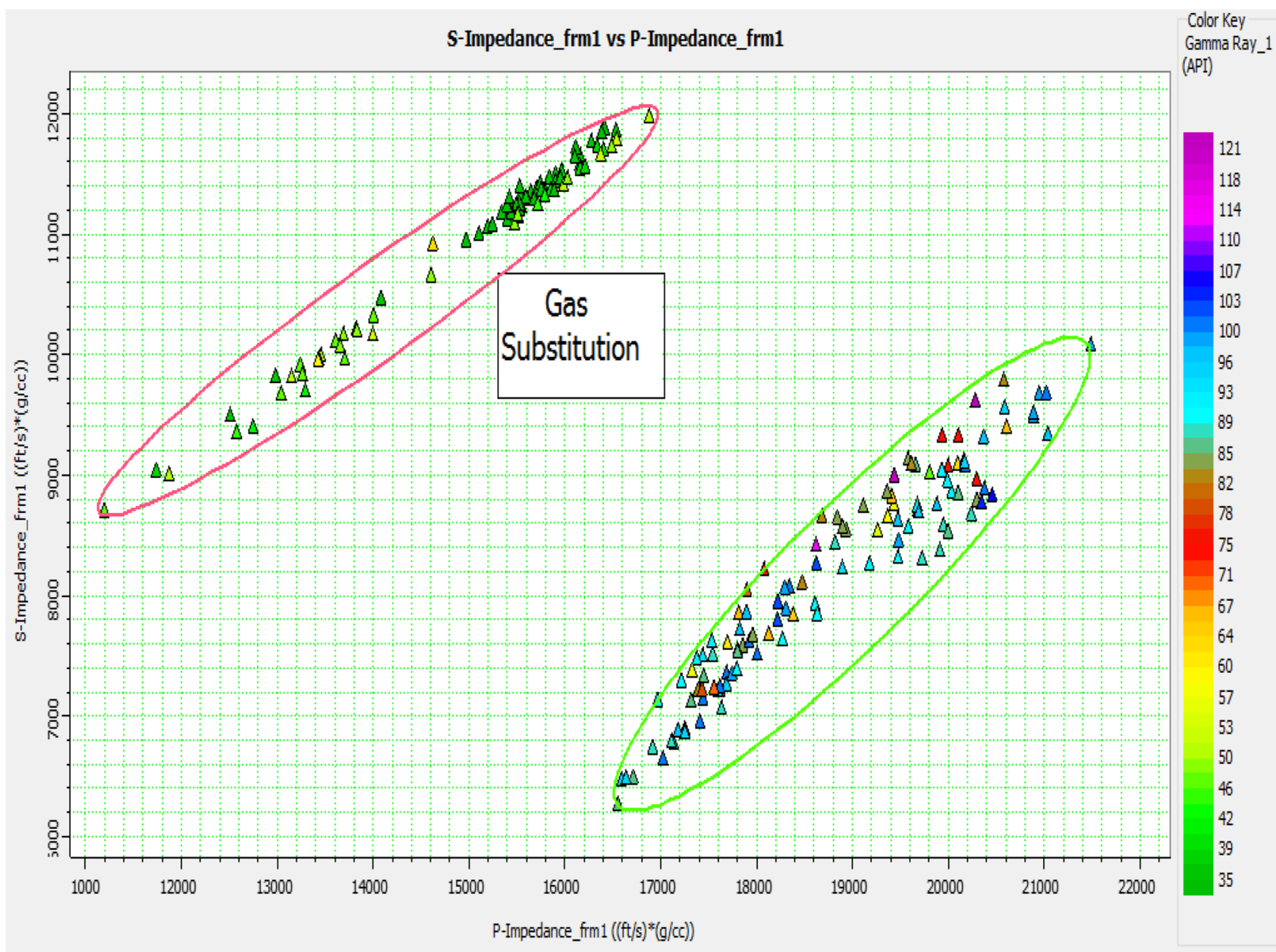

Fig. 15 S-impedance versus P-impedance crossplot space for gas injection

of Figs. 10, 11 and 12, respectively. At the top of the reservoirs, the substitution of gas, brine and oil cause changes in the colours and the generated synthetic traces, which indicate the presence of each fluid injected. For the gas injection shown in Fig. 10, the response of the synthetic traces is such that amplitude increases negatively when compared to the in situ model. The in situ depicts the measure of the three formation fluids present at the point of logging, which is characterized by different colours representing various fluids in the reservoirs. With the injection of $50 \%$ gas into the reservoir, the tops of the two reservoirs, HD3000 and HD5000, are completely filled with green colour indicating low impedance sand which is usually attributed to hydrocarbon-saturated rock. An entirely opposite response is observed in the case where the reservoirs are filled with 50\% brine as shown in Fig. 11. Amplitudes of the generated synthetic traces increase positively, and tops of the reservoirs HD3000 and HD5000 are filled with purple colour. In Fig. 12, the substitution of $50 \%$ oil gives the same synthetic and colour separation as the $50 \%$ gas saturation scenario. The reservoir tops are filled with green colour and the amplitude increases negatively. From the results, hydrocarbon charged sands have been clearly distinguished from background shale/water sand using the colour separation and this agrees with [32] that a standard way of relating P-wave seismic velocity to changes in fluid saturation is to use the Gassmann model.

\subsection{Fluid replacement modelling crossplots}

The model elastic parameters crossplots showing discrimination of the formation fluid from the lithology are shown in Figs. 13, 14, 15 and 16. The crossplot of Fig. 13 presents a separation between the two dominant lithologies in the study area. The crossplot space revealed the sand and shale lithology separated based on the clusters converging into green and cyan to purple colours. In Fig. 14, the separation is between gas-saturated sand and lithology as inferred from gamma ray log colour key. The plots depict separation of gas sand from the plot with low gamma 


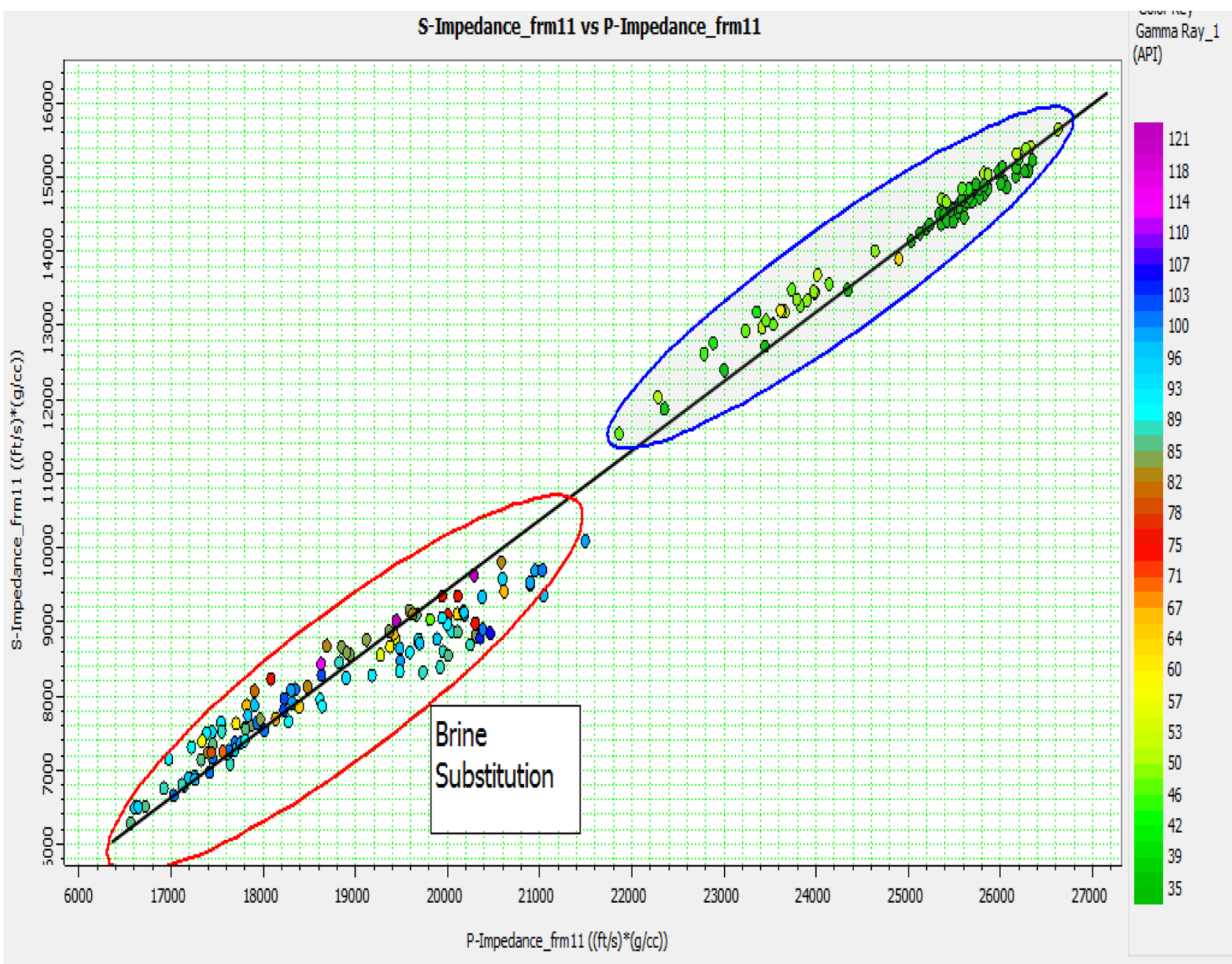

Fig. 16 S-impedance versus P-impedance crossplot space for brine substitution

response circled in pink and the shale bed circled in green polygon with high gamma response. On the other hand, Fig. 15 depicts the crossplot scenario for brine substitution with the fluid and lithology clusters plotting separately along the trend. The substituted brine is marked with red polygon indicating the shale zones. Interpretation based on crossplot results using P-impedance as colour key show separation in the clusters, revealing sand and shale lithologies, and fluid delineating brine filled sand and gas-saturated sands. The result of the synthetic crossplot scenario for oil substitution is shown in Fig. 16. The plots depict separation of oil sand from the plot with low gamma response circled in yellow and the shale bed circled in cyan polygon with high gamma response. Gassmann fluid substitution method adopted in this study gives a better discrimination between fluids in the reservoir unlike the separation observed in the in situ crossplot results.

\subsection{Inverted P-impedance section}

Figure 17 shows the inverted acoustic impedance result carried out in 3D domain to delineate hydrocarbon reservoirs in the seismic section. The interpreted horizons run across the sections identifying the top and base of the reservoir sands of HD3000 and HD5000 with intersecting wells. The inverted impedance cross sections run from a time window of 1400-2000 ms. The inverted acoustic impedance volume $\left(I_{\mathrm{p}}\right)$ correlates well with the inserted $I_{\mathrm{p}}$ curve of wells $X 1$ and $X 2$. Shale beds are characterized in blue and purple colours with the highest $l_{\mathrm{p}}$ values ranging from $2.04 \times 10^{4}$ to $2.38 \times 10^{4} \mathrm{ft} / \mathrm{s} * \mathrm{~g} / \mathrm{cc}$. This lithology lies above the delineated reservoirs across the inverted section with varying event time. The medium to high impedance in red and cyan colours corresponds to brine sands with $I_{p}$ values ranging from $1.88 \times 10^{4}$ to $2.01 \times 10^{4} \mathrm{ft} / \mathrm{s} * \mathrm{~g} / \mathrm{cc}$ close to the base of the reservoirs. The lowest $I_{\mathrm{p}}$ is observed with the green and yellow colours with $I_{\mathrm{p}}$ values ranging from 


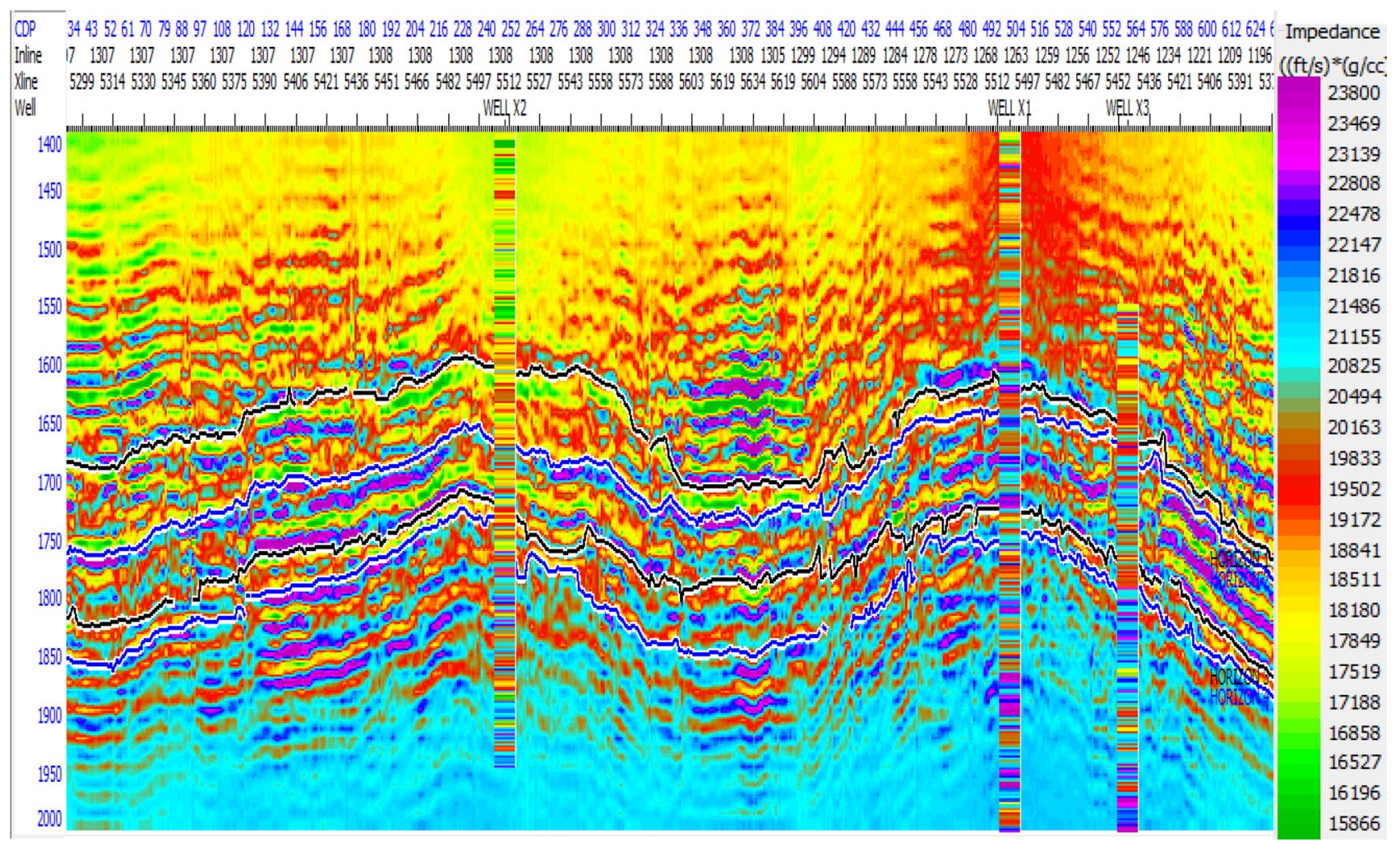

Fig. 17 Inverted P-impedance volume from time window of 1400-2000 ms

Fig. 18 Amplitude slice (Zp) of the horizon from the inverted P-impedance section

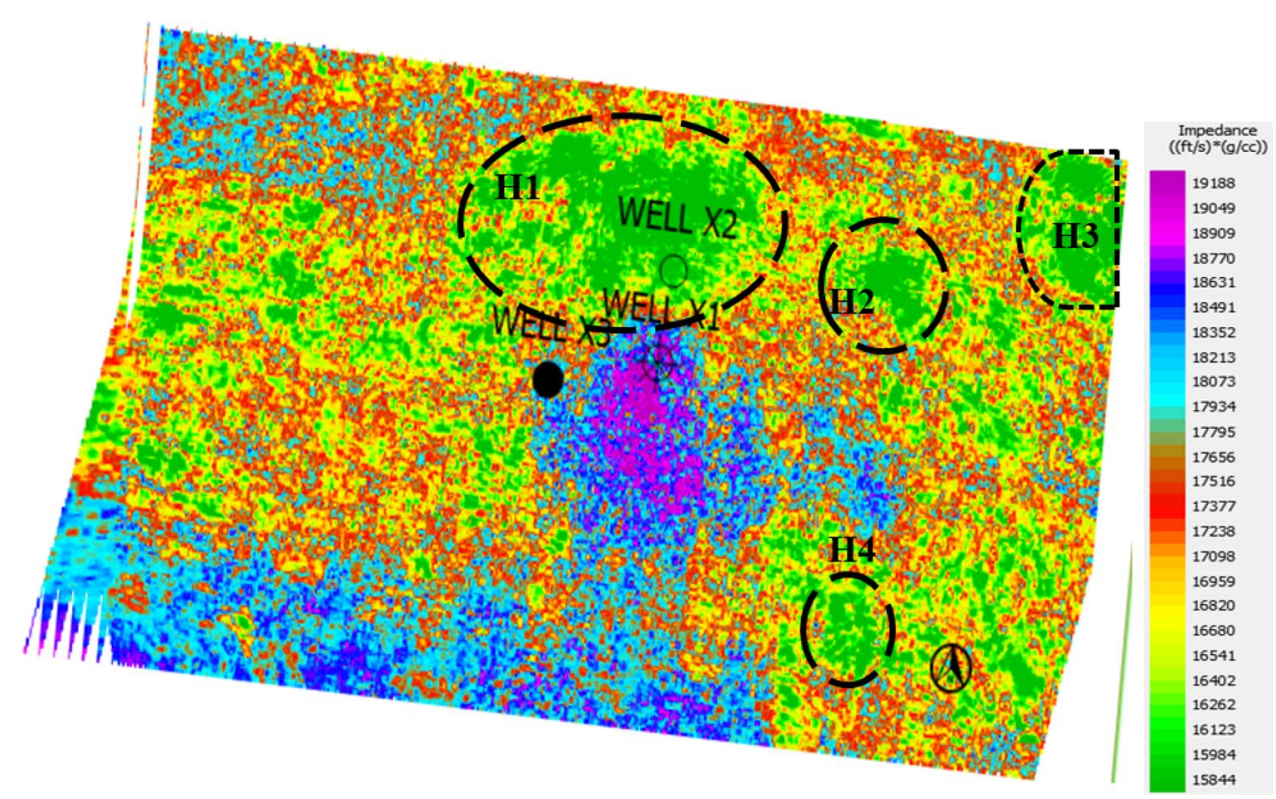

$1.58 \times 10^{4}$ to $1.85 \times 10^{4} \mathrm{ft} / \mathrm{s} * \mathrm{~g} / \mathrm{cc}$. These areas with lowest $I_{\mathrm{p}}$ values are the hydrocarbon-saturated sand as the presence of hydrocarbon decreases $\mathrm{P}$-impedance with more decrease attributed to gas accumulation.

\subsection{P-impedance amplitude $\left(Z_{p}\right)$ map slice}

The acoustic impedance amplitude slice result cut from the inverted 3D seismic volume is shown in Fig. 18. The result depicts probable hydrocarbon-saturated zones, which are marked out in different shapes and labelled as: $H 1, H 2$, 
$\mathrm{H} 3$ and $H 4$. It represents the average amplitude slice from the picked horizons, which correspond to the delineated HD3000 and HD5000 reservoir sand units. From the slice result, probable hydrocarbon accumulation is observed in the zones characterized with low P-impedance in green colour code. These zones are inferred to be hydrocarbon zones based on the low $P$-impedance values ranging from $1.5 \times 10^{4}$ to $1.6 \times 10^{4} \mathrm{ft} / \mathrm{s} * \mathrm{~g} / \mathrm{cc}$. A much more saturation of prospective hydrocarbon accumulation exists around well $X 2$ and the North Eastern part of the amplitude slice section. These two regions depict more pronounced low impedance in green colour. Shale beds are characterized with intermediate P-impedance in cyan to purple colour. The $P$-impedance values within these regions range from $1.7 \times 10^{4}$ to $1.9 \times 10^{4} \mathrm{ft} / \mathrm{s}{ }^{*} \mathrm{~g} / \mathrm{cc}$.

\section{Conclusion}

Gassmann fluid substitution modelling has been successfully applied in delineating and discriminating the formation fluid in $X$-field. Fluid saturation models representing different fluid scenarios in the field have been instituted for the field. These model results and the synthetic scenarios ascertain the relationship between each formation fluid and the expected impedance colour response. The model synthetic served as constraint in mapping probable hydrocarbon accumulated regions in the study area. The 3D P-impedance inverted amplitude map slice depicts the potential of possible hydrocarbon regions. The study further re-establishes the strength of fluid substitution modelling in the characterization of hydrocarbon exploration field in terms of the probable fluid present in any field considered for exploration.

Acknowledgements The authors are grateful to Shell Petroleum Development Company of Nigeria Limited for providing the dataset employed in carrying out this study. We also thank the Hampson Russell Corporation for software used in analysing the data.

\section{Compliance with ethical standards}

Conflict of interest There is no conflict of interest.

\section{References}

1. Fajana AO (2020) 3D static modeling of lateral heterogeneity using geostatistics and artificial neural network in reservoir characterization of ' $P$ ' field, Niger Delta. NRIAG J Astron Geophys 9(1):129-154

2. Dagogo T, Ehirim NC, Ebeniro JO (2016) Enhanced prospect definition using well and 4D seismic data in a Niger Delta Field. Int J Geosci 7:977-990
3. El-Bahiry M, El-Amir A, Abdelhay M (2017) Reservoir characterization using fluid substitution and inversion methods, offshore West Nile Delta, Egypt. Egypt J Pet 26:351-361

4. Umoren EB, George NJ (2018) Time lapse (4D) and AVO analysis: a case study of Gullfaks field, Northern North Sea. NRIAG J Astron Geophys 7:62-77

5. Akpan AS, Okeke FN, Obiora DN (2020) Assessment updated low frequency in delineating bypassed hydrocarbon reservoir: a 4D seismic study of X-field, Offshore Niger Delta, Nigeria. Indian J Sci Technol 13(36):3738-3753. https://doi.org/10.17485/IJST/ v13i36.770

6. Akpan AS, Obiora DN, Okeke FN, Ibuot JC, George NJ (2020) Influence of wavelet phase rotation on post stack inversion: a case study of X-field, Niger Delta, Nigeria. J Petrol Gas Eng 11(1):57-67. https://doi.org/10.5897/JPGE2019.0320

7. Oyeyemi KD, Olowokere MT, Aizebeokhai AP (2017) Evaluation of optimal reservoir prospectivity using acoustic impedance model inversion: a case study of an offshore field, Western Niger Delta, Nigeria. NRIANG J Astron Geophys 6:300-310

8. Omoja UC, Obiekezie TN (2019) Application of 3D seismic attribute analyses for hydrocarbon prospectivity in Uzot-field. Int J Geophys, Onshore Niger Delta Basin, Nigeria. https://doi. org/10.1115/2019/1706416

9. Munyithya JM, Ehirim CN, Dagogo T (2020) Reflectivity and spectral attribute-based reservoir characterization: a case study from "MUN" onshore Niger Delta field. J Pet Explor Prod Technol, Nigeria. https://doi.org/10.1007/s13202-020-00922-4

10. Gommensen L, Mavko G, Mukerji T, Fabricius IL (2002) Fluid substitution studies for North Sea Chalk Logging Data. In: Proceedings of the SEG annual meeting. Salt Lake City, Utah

11. Ejedawe J, Love F, Steele D, Ladipo K (2007) Onshore to deepwater geologic integration, Niger Delta. Shell Exploration and Production Limited, Port-Harcourt

12. Ajaegwu NE, Odoh BI, Akpunomu EO, Obiadi I, Anakwuba EK (2012) Late miocene to early pliocene palynosstratigraphy and Palaeo-environments of ANE-1 Well, Eastern Niger Delta, Nigeria. J Min Geol 48:31-43

13. Ebong ED, Akpan AE, Urang JG (2019) 3D structural modeling and fluid identification in parts of Niger Delta Basin, Southern Nigeria. J Afr Earth Sci 158:103565

14. Evamy B, Herembourne J, Kameline P, Knap W, Molly F, Rowlans P (1978) Hydrocarbon habitat of Tertiary Niger Delta. Am Assoc Pet Geol Bull 62:1-39

15. Short KC, Stauble AJ (1967) Online of the Niger Delta. Am Assoc Pet Geol Bull 51:761-779

16. Weber KJ (1986) Hydrocarbon distribution patterns in Nigeria growth fault structures controlled by structural style and stratigraphy. Am Asso Petrol Geol Bull 70:661-662

17. Weber KJ, Daukoru E (1975) Petroleum geology of the Niger Delta. In: Proceedings of the 9th world congress, vol 2, pp 209-221

18. Stacher $P$ (1995) Present understanding of the Niger Delta Hydrocarbon Habitat. In: Oti MN, Postma G (eds) Geology of Deltas. AA. Balkema, Rotterdam, pp 257-267

19. Nuhu GO (2009) Geology and mineral resources of Nigeria. Springer, Dordrecht, pp 109-112

20. Lawrence S, Munday S, Bray R (2002) Regional geology and geophysics of the eastern Gulf of Guinea, Niger Delta to Rio Muni. Lead Edge 21:1112-1117

21. Smith T, Sondergeld CH, Rai CS (2003) Gassmann Fluid Substitution: a tutorial. Geophysics 68:430-440

22. Avseth $P$, Veggeland $T$ (2015) Seismic screening of rock stiffness and fluid softening using rock physics attributes. Interpretations 3(4):SAE85-SAE95

23. Gassmann F (1951) Elastic waves through a packing of spheres. Geophysics 16:673-685 
24. Sheriff RE (2006) Comment on the definition of a geophysical field in the encyclopedic dictionary of applied geophysics. In: 4th Edn. geophysics

25. Archie GE (1952) Classification of carbonate reservoir rocks and petrophysical considerations. Am Asso Pet Geol Bull 36:218-298

26. Larinov VV (1969) Borehole radiometry. Nedra, Moscow

27. Hilchie DW (1978) Applied openhole log interpretation: golden, Colorado. D.W. Incorporated, Bonn

28. Ghorab M, Mohmad AMR, Nouh AZ (2008) The relation between the shale origin (source and non-source) and its type for Abu Roash formation at Wadi El-Natrun Area, South of Western Desert Egypt. Aust J Basic Appl Sci 2(23):360-371

29. Castagna JP, Greenberg ML (1993) Shear wave velocity estimation in porous rocks; theoretical formulation, preliminary verification and applications. Geophys Prospect 40:195-209
30. Rider M (1986) The geological interpretation of well logs. Blackie, Glasgow

31. Omudu LM, Ebeniro JO (2007) Crossplot and descriptive statistics for lithology and fluid discrimination: a case study from Onshore Niger Delta. In: Presented at the Annual Meeting of NAPE, Abuja

32. Landro M (2010) 4D Seismic. In: Bjorlykke Knut (ed) Petroleum geoscience: from sedimentary environments to rock physics. Springer, Berlin

Publisher's Note Springer Nature remains neutral with regard to jurisdictional claims in published maps and institutional affiliations. 